\title{
Getting the Opportunity to Fly on your own
}

\author{
F. Gisou van der Goot*
}

\begin{abstract}
The author describes the beginning of her independent scientific career in the Department of Biochemistry of the University of Geneva, at a time when Assistant Professor positions did not exist there and female group leaders in the Section of Chemistry were a rare species. Good timing, strong support and an excellent atmosphere are what she remembers. Her stay there was absolutely crucial to her success.
\end{abstract}

Keywords: Department of Biochemistry · Section of Chemistry · University of Geneva

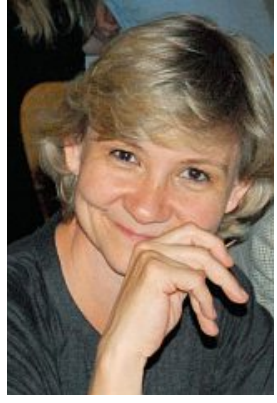

After being trained as a polytechnical engineer in France, I performed a $\mathrm{PhD}$ in Biophysics at the University of Paris VI. From there I moved on for a postdoctoral stay at the European Molecular Biology Laboratory (EMBL) in Heidelberg. Back then my medium-term plan was to do a post-doc for a few years and then to go into industry, as dictated by my engineering training. At the EMBL, I started working on bacterial toxins. More specifically on protein toxins that have the ability to form pores in the plasma membrane of their target cells. These are fascinating proteins that live in two generally incompatible states. They are secreted by the bacterium as a soluble protein. They subsequently bind to specific receptors at the surface of target cells where they then multimerize into ring-like structures and undergo an additional conformational change that exposes hydrophobic surfaces, allowing the complex to insert into the membrane and form a pore. ${ }^{[1]}$ Using biophysical approaches, my interest was to understand how these proteins convert from a soluble to a transmembrane state, a question that has still not been

${ }^{*}$ Correspondence: Prof. Dr. F. Gisou van der Goot Ecole Polytechnique Fédérale de Lausanne Institute of Global Health

Station 15

$\mathrm{CH}-1015$ Lausanne

Tel.: +41216931791

Fax: +41216939538

E-mail: gisou.vandergoot@epfl.ch fully resolved. The success of my postdoc projects combined with the extremely stimulating and international environment of EMBL convinced me that academic research was what I wanted to do in the coming years.

In Heidelberg I met my future husband who was offered a professor position at the Faculty of Sciences of the University of Geneva. I went to Geneva to visit several groups and give seminars in view of finding a second post-doc position. One of the talks I gave was at the Department of Biochemistry, UNIGE. After my seminar, Stuart Edelstein, then head of the Department asked me: "Why don't you start your own group?" In those days, the University of Geneva did not have Assistant Professor positions. Also, not being Swiss, I was not eligible for a START (Swiss Talents for Advanced Research and Teaching) fellowship, which at that time was equivalent to the SNF Professeur Boursier. Stuart Edelstein thus offered me to start my independent group on a Maître Assistant position, which was a unique opportunity especially at the age of 29 . The department would provide me with space, access to all common equipment and a few thousand francs of financial support. The rest would have to come from the SNF. Not having thought much about the future beyond the post-doc, I thought this was an interesting alternative to a post-doc and accepted the offer. Luckily I never thought about what would happen if I did not get my SNF grant. Fortunately, Switzerland and the SNF welcomed, and still do, young scientists unknown to them, as long as their CV met their standards. And so in December 1993 I joined the Department of Biochemistry. This department is part of the Section of Chemistry and not Biology. Chemistry did not host any female group leaders at that time. The status of group leader was actually only how the professors viewed you. Indeed since the notion of Assistant Professor did not exist, I could not participate in Faculty meetings, and could not be the official supervisor of my PhD students. But this was only a very minor annoyance since my colleagues within the department and the section fully acknowledged me as an independent investigator, supporting me as they could.

When I joined the Department, I was fortunate to benefit from additional financial support in the form of a salary for a $\mathrm{PhD}$ student, to which was later added a post-doc and a part-time technician, because of structural changes in the department. Stuart Edelstein reduced the size of his group, after moving his efforts from a wet lab to a computational biology lab. Jacques Deshusses, who had supported me all along, retired and it took time before the Department received the green light to start the search for a new professor. This additional support really gave me the opportunity to take off.

In addition to the material support, the combination of expertise that was available at the Faculty of Science allowed me to evolve scientifically and broaden the interests of my group. We continued our biophysical approaches aimed at understanding the conformational changes that accompany membrane insertion of proteins, and benefited from the arrival of Stefan Matile and Naomi Sakai. ${ }^{[2]}$ But my wish was to also start addressing how bacterial toxins interact with their target cells, how they bind, what cellular mechanisms promote the oligomerization process, how cells sense and react to bacterial toxins (Fig. 1). The problem was that, not having been trained in biology, I had never even seen a cell through a microscope, let alone studied cells by any other means. But my colleagues were extremely patient and helpful, especially Jean Gruenberg and the late Thomas Kreis, from the Department of Cell Biology. This also coincided with the arrival of an excellent post-doc in my lab, Laurence Abrami - whom I could hire only thanks to the support of the department - and who is still working with me at the EPFL, 12 years later. Thanks to 


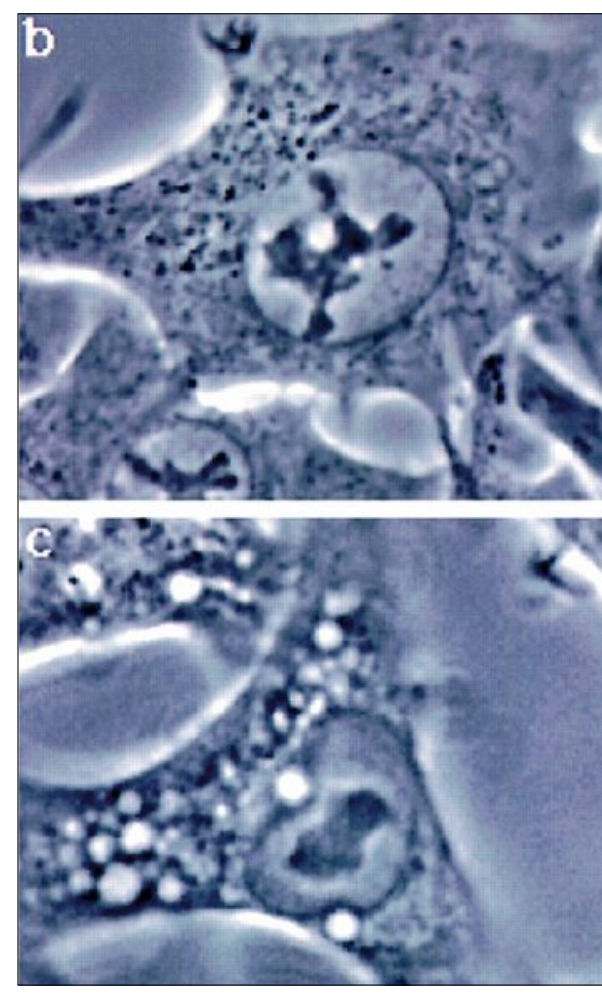

Fig. 1. Mammalian cells submitted to the poreforming toxin aerolysin underwent dramatic cytoplasmic vacuolation (reproduced with permission from ref. [3]).

all these concomitant events, my group moved successfully into the fields of cell biology and cellular microbiology, i.e. the field of host-pathogen interactions. One of our breakthroughs at the time was to show that toxins and pathogens interact with specific domains at the surface of target cells, called lipid rafts. ${ }^{[4,5]}$ This theme fitted well with the preferred outing of different labs of the Faculty of Sciences: rafting in the river Dranse near by (Fig. 2). This effort nicely summarizes the spirit of the time: hard work, fun and strong friendly interactions.

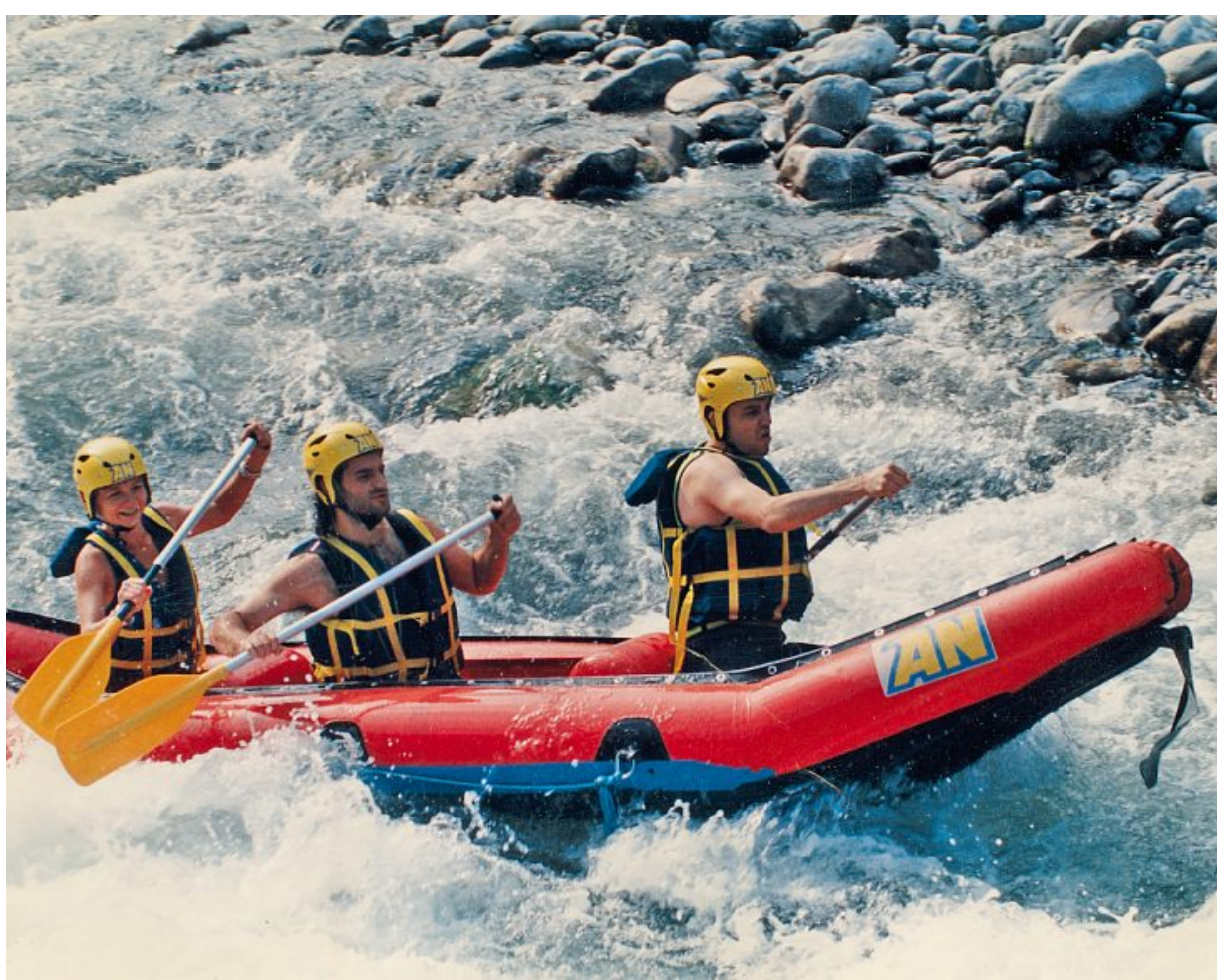

Fig. 2. Spirit of the time. Hard work but team spirit characterized the time. Outing between multiple labs of the Science Faculty to the Dranse river. People in the boat from front to rear: G. Diamantopoulos (Kreis Group), F. Perez (Kreis Group), G. van der Goot.

I cannot finish this remembrance without thanking Jacques Weber, then the Dean of the Faculty of Sciences. He provided me with his full support, did everything so that my Maître Assistant position could be converted into a temporary Maître d'Enseignement et de Recherche (MER) position, to give me the time to find a professorship. This period then allowed me to obtained an Associate Professor position at the Medical School in Geneva, from which I have moved on to the EPFL. The University of Geneva has thus played a determining role in my scientific career.
Received: October 10, 2009

[1] I. Iacovache, F. G. van der Goot, L. Pernot, Bioch. Biophys. Acta: Biomembranes 2008, in press.

[2] I. Iacovache, P. Paumard, H. Scheib, C. Lesieur, N. Sakai, et al., Embo. J. 2006, 25, 457.

[3] L. Abrami, M. Fivaz, P.-E. Glauser, R. G. Parton, F. G. van der Goot, J. Cell Biol. 1998, 14,525 .

[4] L. Abrami, F. G. van der Goot, J. Cell Biol. 1999, 147, 175.

[5] M. Fivaz, L. Abrami, F. G. van der Goot, Trends in Cell Biology 1999, 9, 212. 